\title{
Situating Cornerstone Propositions
}

\author{
Patrice Philie \\ Department of Philosophy, University of Ottawa, Ottawa, Canada \\ Email: pphilie@uottawa.ca
}

Received July 31 ${ }^{\text {st }}$ 2012; revised September $2^{\text {nd }}$, 2012; accepted September $14^{\text {th }}$, 2012

\begin{abstract}
Ostensibly, Wittgenstein's last remarks published in 1969 under the title On Certainty are about epistemology, more precisely about the problem of scepticism. This is the standard interpretation of On Certainty. But I contend, in this paper, that we will get closer to Wittgenstein's intentions and perhaps find new and illuminating ways to interpret his late contribution if we keep in mind that his primary goal was not to provide an answer to scepticism. In fact, I think that the standard reading (independently of its fruitfulness with dealing with scepticism) leads to a distorted view of Wittgenstein's contribution in On Certainty. In order to see that, scepticism will first be briefly characterised, and then I will attempt to circumscribe more precisely the standard reading of On Certainty. In Criticism of the Standard Interpretation, three exegetical arguments against the standard reading are offered-the hope being that the weight of these three arguments, taken together, instils doubt in the reader's mind about the correctness of the standard reading. The paper concludes with an attempt to gesture at the philosophical significance of On Certainty once we set aside the standard reading.
\end{abstract}

Keywords: Wittgenstein; Skepticism; On Certainty; Cornerstone Propositions; Hinge Propositions

Scepticism is not irrefutable, but obvious nonsense if it tries to doubt where no question can be asked.

For doubt can only exist where a question exists; a question can only exist where an answer exists, and this can only exist where something can be said.

Wittgenstein, 1915.

\section{Introduction}

Ostensibly, Wittgenstein's last remarks published in 1969 under the title On Certainty are about epistemology, more precisely about the problem of scepticism. After all, Wittgenstein is here reacting to Moore's "common sense" answer to the sceptic. Moreover, the central focus of these remarks is on Moore's claim to know some propositions (the so-called cornerstones), against the sceptic's claim that these propositions are not known. Wittgenstein's celebrated suggestion is that we do not know these propositions (contrary to what Moore claimed and in agreement with the sceptic), but that nevertheless these propositions play a special part in our conceptual scheme. It is usually agreed that this privileged status is what insulates these propositions from the sceptical threat according to Wittgenstein. Hence, on this "standard" reading of On Certainty, the task of circumscribing a privileged class of propositions is a means towards the end of proving the sceptic wrong-and the accomplishment of that task is the driving theme of the work.

This interpretation is widespread in the literature surrounding On Certainty. For example, Michael Williams, in his penetrateing study of scepticism, talks of an "anti-sceptical strategy" in relation to On Certainty and also, perhaps more cautiously, of a "Wittgensteinian" response to scepticism (Williams, 1991: p. 28). Marie McGinn also appears to accept the standard interpretation when she writes that the "primary aim" of On Certainty is to "steer a course between the sceptic's doubt and
Moore’s dogmatism” (McGinn, 1989: p. 104). ${ }^{1}$ Neil Gascoigne explicitly asserts that "it is clear that through an engagement with Moore's essays, On Certainty constitutes an attempt to respond both to the argument from ignorance (Moore's 'Proof') and the Agrippan argument (Moore’s 'Defence')” (Gascoigne, 2002: p. 143). P. M. S. Hacker is closer to the alternative interpretation to be suggested here-but nevertheless accepts the standard view-when he claims, talking about Wittgenstein's attitude towards scepticism in On Certainty, that the sceptical point of view is "not to be answered by proving that we do know what the sceptic doubts, but rather by showing that the sceptical doubts make no sense” (Hacker, 1986: p. 208). Stroll, in his study of the book (1994: p. 81), claims that what Wittgenstein is "getting at" in On Certainty "leads to a way of thinking about scepticism that is partly directed to those attracted to it, partly to those, like Moore, who wish to reject it”. He also refers to Wittgenstein's "treatment" of scepticism (1994: pp. 8, 166).

What all these interpretations have in common is their attribution of the motivation behind On Certainty, namely that it should be read as a response to scepticism. This is the claim I want to put under pressure here. It should be stressed that it must not be confused with a rebuttal of the claim that Wittgenstein's remarks in that book can be "borrowed" or made to fit an anti-sceptical strategy in a fruitful and interesting way-the pregnant works by the authors just mentioned prove it eloquently. There is nothing wrong with such attempts - they even showcase the fertility of the work. But I contend, in this paper, that we will get closer to Wittgenstein's intentions and perhaps find new and illuminating ways to interpret his late contribution

\footnotetext{
${ }^{1}$ Also: "Wittgenstein, like Moore, Austin and Cavell, accepts that any philosophically satisfactory response to the sceptic must yield an unqualified form of common sense” (McGinn, 1989: p. 101: emphasis mine).
} 
if we keep in mind that his primary goal was not to provide an answer to scepticism. ${ }^{2}$ In fact, I think that the standard reading (independently of its fruitfulness with dealing with scepticism) leads to a distorted view of Wittgenstein's contribution in On Certainty. In order to see that, scepticism will first be briefly characterised, and then I will circumscribe more precisely in The Standard Interpretation of on Certainty, the standard reading of On Certainty. In Criticism of the Standard Interpretation, three exegetical arguments against the standard reading are offered-the hope being that the weight of these three arguments, taken together, instils doubt in the reader's mind about the correctness of the standard reading. The paper concludes in The Purpose of On Certainty, with an attempt to gesture at the philosophical significance of On Certainty once we set aside the standard reading.

\section{Moore and Scepticism}

What is the nature of scepticism in the present context? In the broadest possible terms, the sceptic is this unreal but very nagging philosopher who defends the view according to which we cannot claim to know any empirical proposition. ${ }^{3}$ Let us compare this with Moore's proof in his "Proof of an External World". It is important to bear in mind that Moore's proof is designed primarily to prove the existence of external things, not to prove that we can know empirical propositions. Indeed, Moore stands up, shows his hands, and claims to have proven the existence of external things. ${ }^{4}$ Hence, his proof is directed at those who doubt the existence of the external world, and such a characterisation seems to be more appropriate to describe idealists rather than sceptics. However, Moore's proof bears directly on the issue at hand, thanks to his argument to the effect that his "proof" displays all the features of a real proof. Part of this argument consists in claiming that the premises of the proof are known, hence that Moore knows that he has a hand (contrary to what the sceptic claims). ${ }^{5}$ It is therefore undeniable that Moore's proof is relevant to scepticism as understood here-offering what is in fact a "straight" response to scepticism, that is, one denying what the sceptic is claiming. A useful way to look at the matter is to formulate both Moore's proof and the sceptic's claim in terms of Crispin Wright's I-II-III

\footnotetext{
${ }^{2}$ One must not forget that a lot of interesting and highly relevant work pertaining to On Certainty but, crucially, not exclusively centered around the issue of scepticism is currently being done (see for instance Moyal-Sharrock monograph (2005) and the essays she edited with Brenner (2007). See also Coliva (2010)). The point I wish to make is not affected by the existence of such work. All I wish to argue for is a thesis about the driving theme of On Certainty. It is important to note also that I am not implying that On Certainty is a mere offshoot of the Philosophical Investigations or that it does not say anything over and above PI, etc.

${ }^{3}$ I go along with Stroud's characterisation of the sceptic's main claim: "we can know nothing about the world around us” (Stroud, 1984: p. 39).

${ }^{4}$ Here is Moore's proof: "I can prove now, for instance, that two human hands exist. How? By holding up my two hands, and saying, as I make a certain gesture with my right hand, 'Here is one hand', and adding, as I make a certain gesture with the left, 'and here is another'. And if, by doing this, I have proved ipso facto the existence of external things, you will all see that I can also do it now in numbers of other ways: there is no need to multiply examples.” (Moore, 1939: pp. 165-166).

${ }^{5}$ These explanations about Moore's target and its relation to scepticism are worth mentioning. Indeed, Moore's proof is often understood and assumed as being directed towards scepticism as defined here, but this does not seem quite right. The sceptic (as understood here) does not need to deny the existence of external things. What he denies is that we can know things about the world, not that the world exists.
}

template. Here is Moore's proof as understood by Wright ${ }^{6}$ :

1) It looks to me as if I have a hand.

2) I have a hand.

3) There is a material world.

In this “proof”, 1) justifies 2) and 2) justifies 3). The sceptic, however, is likely to point out that both inferential moves are not warranted. Let us start with the move from 1) and 2) to 3). Moore, according to the sceptic, got things the wrong way round: a correct demonstration of "I have a hand" should start with, or assume, the claim that there is a material world. We cannot start with how things appear to us and then infer from these appearances that things are as a matter of fact thus-and-so in order to prove that there is a material world. On the contrary: it is only by presupposing or having already established that there is a material world that a knowledge-claim such as "I have a hand" is possible at all. The move from 1) to 2) is likewise unwarranted according to the sceptic: she will argue, contra Moore, that appearances can always be misleading and that we cannot trust our senses - this is in fact the main argumentative weapon in the sceptic's arsenal. Since the claim that there is a material world can only be proved with claims such as 2), it follows that establishing what Moore wants to establish is impossible. Hence the sceptic's reaction to Moore's proof is two-pronged: she holds that Moore's proof does not succeed in establishing that he knows he has a hand, and also, independently of the success of this demonstration, that it does not anyway succeed in establishing that there are external things. Hence we can identify two kinds of scepticism, and it will be useful to distinguish them by name: I will call the kind of scepticism that takes issue with the move from type-I to type-II propositions knowledge scepticism, and the kind of scepticism that takes issue with the move from type-I and type-II to type-III propositions external world scepticism.

Wright's characterisation of Moore's proof and its correlated sceptical reaction is a template and can be applied to any empirical knowledge-claim, in which case 1) and 2) will differ in content. It will be useful to assign types to 1), 2) and 3) above. A type-I proposition, in this context, will be any proposition pertaining to how things appear to a subject. A type-II proposition will be a proposition that states that things in the empirical world are as they seem to be in its associated type-I proposition. A type-III proposition will be a proposition whose status as a justified belief, according to the sceptic, is presupposed for the establishment of any type-II proposition. ${ }^{7}$

\section{The Standard Interpretation of on Certainty}

Wittgenstein writes, in the opening lines of On Certainty: “1) If you do know that here is one hand, we'll grant you all the rest”.

In terms of the I-II-III template, Wittgenstein starts by sug-

\footnotetext{
${ }^{6}$ See Wright (2002, 2004a). Moore's proof as stated in "Proof of an External World" starts with 2), but Wright points out that the sceptic is likely to point out that 1 ) is a necessary premise that should be added: 'The sceptic will insist that Moore did not formulate his 'proof' properly - that he begins in the wrong place, since his premise is something which rests on more basic evidence and is thus more properly viewed as a lemma" (Wright, 2004b: p. 26). ${ }^{7}$ It should be noted that this I-II-III schema can also be adapted to other forms of scepticism, namely scepticism about other minds and scepticism about induction. This generalisation is what prompts Wright to suggest a unified strategy against scepticism. However, we need not, for the purposes at hand, go into these details here.
} 
gesting ("all the rest") the consequences of establishing that one can know a type-II proposition. But what are these consequences? There is an ambiguity here. Firstly, Wittgenstein could be referring to Moore's objective in his "Proof of an External World", namely the establishing of the existence of things external to the mind. Secondly, he could also be referring to what Moore is trying to show in "A defense of Common Sense", namely that he knows some propositions with certainty. Indeed, both objectives would be achieved if Moore really knew that he has a hand. Either way-Wittgenstein was perhaps implying both consequences - the conditional is an indication that this kind of knowledge-claim will be the focus of the discussion. Indeed: as is well-known, it will be the main point of Wittgenstein's remarks in On Certainty taken as a whole to study what it means to say that in normal cases, we do not know such things. ${ }^{8}$ The second remark sets the stage in that regard:

"2) From its seeming to me-or to everyone- to be so, it doesn't follow that it is so.

What we can ask is whether it can make sense to doubt it”.

This remark is seminal for the rest of the book: indeed, it raises the fundamental issue of the meaningfulness of doubting some empirical propositions, an issue on which Wittgenstein returns again and again and on which the plausibility of everything else he says depends. But $\S 2$ is also ambiguous. If we consider what he said in $\S 1$, Wittgenstein is talking about a type-II proposition ("here is a hand") and its relation to a type-I proposition ("it seems to me as if I have a hand"). On this reading, the proposition whose status is under study is a type-II proposition. But if we consider $\S 4$, in which Wittgenstein discusses "I know that I am a human being" and puts under pressure the meaningfulness of that claim, then he could as well be discussing type-III propositions. ${ }^{9}$ I mention this because the following point is not often remarked: in Moore's proof, his 'here is one hand' is one for which, according to Wittgenstein, doubt is not meaningful-namely a "cornerstone" —and this fact is worth noticing since the "proof" would not have the strength it is intended to have if the type-II proposition was rather "there are 5 pennies in my pocket". ${ }^{10}$ Hence, when the sceptic insists-as Wright contends she should - to add the type-I proposition in Moore's proof and then exploits the gap between the type-I and the type-II proposition, she is doing so in relation to a special type, so to speak, of type-II proposition, namely one that is a cornerstone proposition according to Wittgenstein. This clearly shows that a Wittgensteinian cornerstone

\footnotetext{
${ }^{8}$ One way to characterise the distance between my reading of On Certainty with the standard one would be the following: I agree that Wittgenstein tries to establish that we do not know a certain class of propositions and that this has important consequences for scepticism. However, I think that what he is mainly striving at is to illuminate the status of these propositions and their situation in our conceptual scheme. It does not take Wittgenstein-or so I want to suggest here-676 remarks to (merely) establish that we cannot be said to know a certain kind of proposition. The bulk of his effort consists in trying to understand, to describe their role and their peculiar status.

${ }^{9}$ It is sometimes difficult to classify propositions in the I-II-III schema. "I know that I am a human being” belongs to that recalcitrant category. Indeed, it cannot be, in a natural way, said to be a proposition supported by a type-I proposition. But it does not have the generic character of a typical type-III proposition either. Wright characterises such proposition as "supported byby normal standards - an overwhelming body of evidence, whose significance would have to be overridden if they were doubted" (Wright, 2004b).

${ }^{10}$ Wright is a notable exception. He carefully (Wright, 2004b: pp. 38-47) distinguishes between the different kinds of cornerstone propositions discussed by Wittgenstein.
}

is not necessarily a type-III proposition: some type-II propositions are also to be excluded from doubt, and this must be kept in mind when evaluating the convincingness of Moore's "proof" and Wittgenstein's reaction to it. When he raises the question of the intelligibility of doubting a proposition on the basis of things seeming thus and so in §2, Wittgenstein is presumably starting to draw a cleavage between "ordinary" type-II propositions and cornerstone propositions such as "I have a hand". This dialectical issue between Wittgenstein and the sceptic is important, since if Wittgenstein can convincingly show that some type-II propositions cannot be doubted, he will have eliminated one of the sceptic's main weapons, namely her claim that since every and any empirical proposition can be doubted (because no type-I proposition can ever ground adequately a type-II proposition), we do not know anything. In any case, Wittgenstein is in the business of examining the status of cornerstone propositions. On this particular and crucial point in relation to Wittgenstein's intentions in On Certainty, everyone-including the present writer-is in agreement.

From what has been said so far, it is very tantalising to interpret On Certainty as a work of traditional epistemology, concerned mainly with replying to the sceptical threat. Indeed, Wittgenstein had started to think about the issues making up the bulk of On Certainty upon his reading of Moore's papers, which are directly addressing the sceptic. Moreover, it has just been pointed out that one of the main topics of the book is about the possibility of doubting some propositions which are central to our conceptual scheme. If some propositions cannot be meaningfully doubted, then the sceptic's dialectic cannot get off the ground, since her main argumentative strategy is to say that any and every proposition can be doubted, and hence cannot be established as known (I shall have more to say on the relation between knowledge and doubt below).

An instance of the standard reading of On Certainty sees it as a sceptical response ${ }^{11}$ to scepticism (whereas Moore's is a straight one). According to that reading, Wittgenstein accepts the sceptical conclusion according to which cornerstone propositions can never be justified. However, even if we're not justified, we nevertheless possess another, weaker kind of warrant for them: we are entitled to them. We can "accept" them without doing any of the usual evidential work that is required for normal, non-cornerstone empirical propositions, and this "free" acceptance $^{12}$ is warranted since these cornerstone propositions are necessary for thought and cognitive endeavours. So on this interpretation, the sceptic is right when she concludes that we are not justified in claiming to know cornerstone propositions-it's just that her conclusion is not as dramatic as she takes it to be. To put it in relation to Moore's proof, Wittgenstein is arguing, according to this reading, against Moore that type-III propositions can neither be proved nor known, and in that sense the sceptic is right. But the sceptic's dramatic conclusion-that nothing can be known since all knowledge depend on type-III propositions and the latter are not knowable is hasty since we possess a warrant for cornerstones and this warrant is enough to give us a good conscience about our cognitive practice and our claims to know type-II, "normal” em-

\footnotetext{
${ }^{11}$ In his recent writings on entitlement, Wright champions that interpretation (2002, 2004a, 2004b).

${ }^{12}$ This is what prompts Wright (2007) to talk of a "Welfare State Epistemology" with regard to these propositions.
} 
pirical propositions.

What is common to most readings ${ }^{13}$ of On Certainty (including the one just mentioned) is their understanding of the dialectical place of cornerstone propositions. ${ }^{14}$ They are seen as mainly motivated by a desire to provide an answer to the sceptical threat, in such a way as to make it almost natural and inevitable to read On Certainty as a work whose primary target is scepticism. Interpreted along these lines, Wittgenstein is here offering an argument against scepticism: while the sceptic contends that everything can be doubted or is not justified, Wittgenstein enters the debate and offers an articulated and argumentative reply to the effect that contrary to what the sceptic holds, not everything can be meaningfully doubted. The reason why not everything can be doubted-always assuming the standard reading - is that some propositions form the backbone of our conceptual scheme in the sense that they make the game of giving and asking for reasons possible. It is this feature that is responsible for their privileged status.

\section{Criticism of the Standard Interpretation}

There are many reasons to resist that reading of On Certainty. In what follows, I will identify and discuss three of them:

- In his Philosophical Investigations and other writings leading to it, Wittgenstein had already "dealt" with scepticism. It would thus be incongruous, at best, if he devoted his very last remarks to pursue (or at best to deepen) an already visited theme.

- The standard reading naturally leads to interpret Wittgenstein as advancing a kind of transcendental argument, and this is in tension with his philosophical outlook.

- More generally, the claim that Wittgenstein is mainly concerned, in On Certainty, with elaborating a response to the sceptical threat implies that he is in the traditional philosophical arena, tackling a traditional problem. But this is inconsistent with a crucial aspect of his so-called "later" philosophy, namely his professed quietism.

\section{Knowledge Scepticism}

Let us begin with the first point. I will start with the first form of scepticism, namely knowledge scepticism. According to a venerable tradition $^{15}$ of Wittgensteinian interpretation, the

\footnotetext{
${ }^{13}$ Rush Rhees is a notable exception. See in particular the notes of his seminars as compiled by D. Z. Phillips in Rhees (2003). The present paper is written while having in mind the spirit, if not the letter, of Rhees' lifelong investigations pertaining on Wittgenstein's so-called "third" masterpiece. It could be said that Rhees did not make a case to the effect that Wittgenstein's thoughts in this set of remarks are not about scepticism because it was obvious for him that Wittgenstein was primarily interested in something else-namely our human cognitive condition, of which more in the last section.

${ }^{14} \mathrm{~A}$ note on the expression "cornerstone proposition" is in order here. According to some interpreters-notably Stroll (1994) - cornerstones are precisely special in that they are not propositions. However, since I wish in this paper to remain neutral on this question, I will continue to use the consecrated expression "cornerstone proposition" without thereby committing myself to a propositional understanding of cornestones.

${ }^{15}$ Stanley Cavell's The Claim of Reason is the locus classicus of this strand. More recent writings influenced by Cavell's sophisticated reading include Andrea Kern's and Marie McGinn's contributions in the collection of essays on Wittgenstein and Scepticism edited by D. McManus (2004). In what follows, I do not claim to follow Cavell's interpretation-perhaps my interpretation diverges from his, but the spirit is preserved in that I agree with Cavell about the link between scepticism and what Wittgenstein is aiming at in his Philosophical Investigations. Entering into an exegesis of Cavell's views would require a separate article.
}

celebrated "private-language argument" of the Philosophical Investigations and what comes before it in the book has important ramifications with regard to the "problem" of knowledgescepticism. This tradition of Wittgensteinian interpretation deserves to be taken seriously. Indeed, in the course of showing the impossibility of a private language, Wittgenstein is led to argue against a pervading view of the mind, that of an 'internal' theatre in which private sensations are accessible through some kind of inner perception (the "mind's eye", to use an evocative and established expression). This conception of the mind finds its source in Descartes, the father of modern epistemology. That the birth of modern epistemology - with its obsession with knowledge-scepticism - and this conception of the mind come simultaneously in the history of ideas is not a coincidence. Indeed, Cartesian doubt finds its source in the idea that we have no guarantee that the information about the world obtained through our senses is trustworthy. Its lack of trustworthiness stems from the fact that all we can be certain of are our sensations. To move from what the world appears to be thanks to our private sensations to the claim that the world really is thus-andso is an inferential step that can never be warranted due to the possibility of error, malicious daemon, evil genius-whatever standard sceptical scenario you might imagine. A crucial premise of knowledge-scepticism thus conceived is that our access to the world is necessarily mediated by the possession of these private "representational" items (whether they are labelled "sense data", "sensations", or "ideas"). It is from the problematic inferential step from "things appear to me as being thusand-so" (thanks to the private, representational items) to "things are thus-and-so" that knowledge-scepticism finds its source. To put it in terms of the I-II-III template, knowledge-scepticism is possible because we can never be justified in inferring type-II propositions from type-I propositions.

The exegetical work has already extensively been done to show that Wittgenstein is indeed arguing against that Cartesian picture of the mind. ${ }^{16}$ Nevertheless, it would be helpful to study a few remarks of the Investigations that are particularly relevant in relation to scepticism and certainty. Let us have a look at an important passage (for the present purpose) of the Investigations, one related to our understanding of colour-words:

"273. What am I to say about the word 'red'?- that it means something "confronting us all" and that everyone should really have another word, besides this one, to mean his own sensation of red? Or is it like this: the word 'red' means something known to everyone; and in addition, for each person, it means something known only to him? (...)

275. Look at the blue of the sky and say to yourself 'How blue the sky is!'-When you do it spontaneously-without philosophical intentions - the idea never crosses your mind that this impression of colour belongs only to you. And you have no hesitation at exclaiming that to someone else. And if you point at anything as you say the words you point at the sky. (...)”

Here Wittgenstein is saying, in essence, that it is a mistake to say, when we use colour words to represent the world, that their

\footnotetext{
${ }^{16}$ Rorty's interpretation of Wittgenstein as criticising the Cartesian picture of the mind in his (1979) has been highly influential. While I agree with Rorty on this particular point, I wish to distance myself from his anti-foundationalist interpretation of Wittgenstein. Incidently, I also wish to distance myself from foundationalist interpretations - such as Stroll (1994) — since the attempt to categorise Wittgenstein as either a foundationalist or an anti-foundationalist seems to imply ascribing to him a predominant concern with scepticism. In any case, I would like to remain neutral on this issue for the time being, if only for the sake of trying to gain a fresh perspective.
} 
use is ultimately justified through the mediation of private items of consciousness, of "sense data". To paraphrase one of Wittgenstein's well known remarks, when we say that something is red, "we do not stop anywhere short of the fact", but we mean this-is-red (§95). We are tempted, when we do philosophy, to "assume a pure intermediary between the propositional signs and the fact” (§96). ${ }^{17}$ But this is, Wittgenstein says, a "chimera" (ibid.) —in other words, there is no such thing as a "representationalist" interface between us and the world.

The foregoing is a picture painted in broad strokes, no doubt about it. But it could be argued that some of the most important and lasting movements of $20^{\text {th }}$-Century philosophy have been concerned with criticising that picture. Indeed, if its contours are adequate, that picture has been the target of philosophers such as Wittgenstein, Heidegger, Sellars, and, closer to us, Davidson, Rorty, and McDowell. All these philosophers jettison the Cartesian conception of the mind and try to show that the result of doing without that conception reveals either that knowledge-scepticism is a pseudo-problem or that scepticism is futile and uninteresting.

In any case, it is difficult to dispute that Wittgenstein is criticising the Cartesian picture of the mind in the Investigations. If this is right, and if that Cartesian picture includes the "representational" role of intermediary private entities such as sense data (or any other conception of the "Given"), then Wittgenstein is targeting a conception of the mind that has been underlying modern philosophy for four centuries. Since that concepttion of the mind made a kind of scepticism possible-notably, the knowledge-scepticism addressed by Moore and by the I-II-III template- then it seems fair to say that Wittgenstein, in the Philosophical Investigations, had "dealt" with knowledgescepticism and revealed it for what it was-a pseudo-problem that should never have surfaced in the first place.

\section{External World Scepticism}

What I have been arguing so far is that Wittgenstein, by the time of the Philosophical Investigations, had the complete framework to address the issue of knowledge-scepticism. It remains, however, to get to grips with the other kind of scepticism, namely what I have called external world-scepticism. This kind of scepticism takes issue with the step from type-II to type-III propositions and claims that we cannot be said to know that there is an external world since in order to establish that, we have to rely on type-II propositions such as "I have a hand" or "this chair is orange" (that is, both types, so to speak, of type-II propositions - the ones respectively identified by Moore as 'certain' and the ordinary ones). But such a reliance leads to a circularity, since in order to be said to know a type-II proposition, one must already have established that there is an external world. But one can only do that on the basis of a type-II proposition-we're caught in a vicious circle. Does the Investigations have the resources to deal with that second kind of scepticism? I wish to argue that it does.

Let us reflect here that the key idea in relation to external world-scepticism, in On Certainty, is to stress the peculiar nature and role of statements such as "I have a hand" and "there is an external world". There is no consensus as to what, exactly, is the status assigned to these propositions in On Certainty. Are

\footnotetext{
$\overline{{ }^{17} \text { McDowell stresses these passages in his own perspective on scepticism, }}$ resting on his version of a direct realism (see in particular Mind \& World, page 27 , where he invokes these remarks).
}

they rules of grammar? ${ }^{18}$ Are they meaningless? ${ }^{19}$ This is, obviously a key issue - not only for the debate around scepticism of any kind, but also with regards to the favoured reading here, namely with respect to an investigation about the human cognitive condition. What I would like to point out is that it is agreed on all sides that Wittgenstein's fundamental idea here is that such propositions cannot be meaningfully be doubted, and for that reason we cannot be said to know them. It also leads to the ideas that these propositions have a special role for us and also that since they cannot be doubted, they do not stand in need of justification. They are outside the game of "giving and asking for reasons". How this fundamental idea is worked out in detail in On Certainty is, as mentioned, a matter of dispute. ${ }^{20}$ However, the fundamental idea, independently of the precise pedigree it takes at the time of On Certainty, is in itself enough to discard the meaninfulness of external world-scepticism. I will now try to show that this connection is already made in $P I$.

In the Philosophical Investigations, Wittgenstein discusses the notions of doubt and knowledge in relation to pain:

"246. In what sense are my sensations private?-Well, only I can know whether I am really in pain; another person can only surmise it.- In one way this is wrong, and in another nonsense. If we are using the word 'to know' as it is normally used (and how else are we to use it?), then other people very often know when I am in pain.-Yes, but all the same not with the same certainty with which I know it myself!- It can't be said of me at all (except perhaps as a joke) that I know I am in pain. What is it supposed to mean-except perhaps that I am in pain?

Other people cannot be said to learn of my sensations only from my behaviour-for I cannot be said to learn of them. I have them.

The truth is: it makes sense to say about other people that they doubt whether I am in pain; but not to say it about myself”.

Let us examine this key passage carefully. The first thing to point out is that Wittgenstein is not denying that sensations are private, but rather the sense in which they can be said to be private. They are not private in the sense that only the one who feels the pain can "really" know that he's in pain (the "really" should be a red herring here-Wittgenstein seems to take it as a pointer that we're talking metaphysically, that language is on vacation). In fact, it's the other way round: other people can know that someone else is in pain, and the one who is in pain cannot, usually, be meaningfully said to know it. Wittgenstein makes it clear, in the last sentence of the remark, that the reason why the one who is in pain cannot be said to know it is because he cannot doubt it. In these remarks of the Investigations the crucial connection between knowledge and the possibility of doubt is made. It is then natural to apply the fundamental idea to "I have a hand" and "there is an external world". Indeed, that connection is repeatedly reminded to us in On Certainty. In the first two remarks of that book discussed in the first section of this paper, Wittgenstein makes it in relation to Moore's "knowledge" that he has a hand: it is said there, in essence, that one cannot know that one has a hand because it does not make sense for one to doubt it. In On Certainty, Wittgenstein does not primarily try to convince us that we cannot doubt such propositions on the basis that we cannot be said to know themthat is, he does not try to convince us of their special status: he

\footnotetext{
${ }^{18}$ See Coliva (2010) and Wright (1985) for this kind of interpretation.

${ }^{19}$ See Williams (1991) for this kind of interpretation.

${ }^{20}$ If my reading of OC is correct, then the elucidation of the status of cornerstones is what the book is all about.
} 
is rather interested in uncovering the nature of that special status and the role it plays in our form of discourse (more on this in the last section of this paper).

In terms of the I-II-III template, once propositions such as "I have a hand" and, even more obviously, "there is an external world", are shown to be outside the game of "giving and asking for reasons" because they cannot be doubted, external worldscepticism cannot get off the ground. Indeed, this kind of scepticism requires that such propositions be just like any other empirical propositions since it rests on the possibility of asking meaningfully: "on what ground can one be said to know that there is an external world or that one has a hand?”. Showing that type-III propositions and some type-II propositions cannot neither be doubted nor known implies that there is no sceptical problem of trying to establish proper justification for type-III propositions such as "there is an external world". The key is to see that the connection between knowledge and the possibility of doubt is already there in the Investigations - in fact, it is already there in the Blue Book. ${ }^{21}$

Let us briefly recapitulate: in the Philosophical Investigations, Wittgenstein has all the elements he will ever need to show that scepticism is a pseudo-problem. The driving theme of this masterpiece-the deconstruction, so to speak, of the Cartesian picture of the mind-leads Wittgenstein to discuss a cluster of issues that are directly related to scepticism as traditionally conceived, namely the issues of privacy, of understanding, and of the role of mental images. These considerations lead to a recognition that knowledge-scepticism is not a philosophical problem. In that book, Wittgenstein also makes the crucial connection between knowledge and the possibility of doubt which is fundamental for dealing with external worldscepticism. It would be, in my opinion, irresponsible to ignore how these themes of the Philosophical Investigations resonate with scepticism. But if they do resonate in this manner, then is it plausible at all to hold that the main thrust of On Certainty is to revisit scepticism, the difference merely being, presumably, that he does so through a different set of considerations?

\section{The Transcendental Reading}

The second reason why On Certainty should not be read as a work whose primary target is scepticism in the aforementioned sense is the following. Interpreting On Certainty along the lines of the standard reading makes it very tempting to see it as putting forward a transcendental argument against scepticism. The reason is this: if On Certainty is taken to put forward the view that there are some propositions that cannot be doubted in virtue of their special role in our conceptual scheme, and if this claim is taken to be made against the sceptic's contention that any proposition can be doubted, then Wittgenstein is here defending a view about the nature of language, about its essence and its conditions of possibility. This is the case if we reflect on the dialectic underlying the work according to the standard interpretation: the sceptic argues that any empirical proposition-type-II or type-III-can be doubted, hence that knowl-

\footnotetext{
${ }^{21}$ See the Blue Book, page 30, where Witgenstein discusses the use of an expression such as "I know what I wish": "Of course I know" could here be replaced by "Of course there is no doubt" and this interpreted to mean "It makes, in this case, no sense to talk of a doubt". In this way the answer "Of course I know what I wish" can be interpreted to be a grammatical statement." Note here that Wittgenstein seems to be gesturing towards the rule-like nature of such statements (but just gesturing-a fuller description of how it works precisely is the topic of On Certainty).
}

edge is impossible. Wittgenstein, on this interpretation, set down to work and tried to prove that this is not the case by writing the remarks contained in On Certainty. The objective was thus to show that contrary to what the sceptic claims, there are some propositions that are immune from doubt. If Wittgenstein can make a case that such propositions exist, he will have revealed scepticism as false (or nonsensical, depending on the version of the favoured reading). In On Certainty (always according to the interpretation under study), he shows the existence of such propositions by pointing out that our cognitive endeavours - more broadly the language game of giving and asking for reasons-depend for their very possibility on there being such privileged propositions, immune from doubt and outside the arena of giving and asking for reasons. Thus it is a condition of possibility of language, or thought, that there are such propositions. Since thought exists (since the language game in question exists), and since its existence requires that some propositions be exempt from doubt, then scepticism is false (or nonsensical).

The problem is that this line of thought attributed to Wittgenstein has the form of a transcendental argument. ${ }^{22}$ Its aim is to identify essential features of language and thought by starting off with general, accepted facts about language and thought - this being followed by an examination of what makes these facts possible, that is, an inquiry into their conditions of possibility. However, it is not a very controversial exegetical claim to affirm that one of the main feature of Wittgenstein's philosophy of the 'second' period is that it is resolutely antitranscendental and anti-essentialist. In the Tractatus, he was under the spell of essentialism and he was trying to find the essence of logic (of language and thought). But in his later work-notably the Blue Book (passim) and the Philosophical Investigations (§§ 89-133) - he is pointing the way towards a way of philosophising that does without such pretensions. The goal of philosophy, for Wittgenstein, is to describe, not to say anything "surprising". A transcendental argument is not designed to merely describe a phenomenon, but typically reaches a substantial conclusion, and has a normative aspect-the result being that we are compelled to accept the conclusion, however surprising it can be or even counter-intuitive.

\section{Wittgenstein's Quietism}

The third exegetical problem related to the standard reading I would like to examine is the following. If we assume that Wittgenstein is trying in On Certainty to solve a traditional philosophical problem, then we are forced to dismiss a central claim of his later philosophy-his quietism. It is uncontroversial that Wittgenstein would conceive of scepticism as being a traditional philosophical problem generated by a misuse of grammar-generated, that is, by an inappropriate use of expressions containing the concepts of knowledge, doubt, certainty and others. So there is no doubt that his position on the nature of philosophy and of philosophical problems-as exposed in the Philosophical Investigations §§ 89-133-precludes him from any attempt to address scepticism in the way discussed in the first section of this paper.

\footnotetext{
${ }^{22}$ See Stern (2000), chapter 3, and especially pages $87-89$. Stern is prudent in that he does not seem to endorse the view that Wittgenstein is a "transcendentalist" but he does acknowledge and discuss there the extent to which Wittgenstein can be interpreted as putting forward a transcendental argument in On Certainty.
} 
The key concern, of course, is whether this is merely Wittgenstein's "official" position, to be contrasted with what he actually does in his later work (including in the Investigations and in On Certainty). Indeed, his celebrated "rule-following considerations" and his claims about the nature of privacy and self-knowledge have often been interpreted as revealing the dysfunctional aspect of his later contributions: on the one hand, we have Wittgenstein's dramatic position on the nature of philosophy-his therapeutic stance and his claim that traditional philosophy is created by a misuse of grammar-which should forbid him to engage in theoretical philosophising, and on the other hand we have immensely influential and original "theories" about, e.g., the nature of the mind and about the most pressing epistemological issue of modern times (scepticism). This way of looking at the matter, however, is completely misguided. This issue has been discussed quite extensively in the contemporary literature. I agree with Crispin Wright's analysis, in which he resolves the tension by pointing out, with respect to the Cartesian picture of the mind, that Wittgenstein's criticism of this picture is not to be seen as a bit of philosophical theorising, but rather as a necessary step towards recognising it for what it is, i.e., a "bad" picture resulting from misinterpretations of the grammar of words and concepts belonging to a certain family. ${ }^{23}$ It is crucial to remember that he does not replace the Cartesian picture with another (better, more accurate) one. Rather, Wittgenstein lets us see that there is nothing special about the nature of the mind as far as philosophy is concerned, there is no mystery and nothing to be explained, since everything lays open to view: it's a matter of looking at things in the right way, not a matter of finding the 'right' theory about the mind and intentionality.

The same can be said about his attitude towards scepticism. That issue is not to be "solved" (because there is no meaningful 'problem' awaiting a solution). The mystery is not that we seem unable to answer the sceptic-it's rather that there is an appearance of mystery (the mystery of scepticism). The role of the philosopher is to show that this mystery is a chimera. If this is right-if Wittgenstein's essential attitude towards scepticism is to treat it as senseless (unsinnig) - then one upholding the standard interpretation criticised here would thus be committed to the claim that the main thrust of On Certainty is to reveal scepticism as a pseudo-problem. But this seems, at best, an odd thing to say-the remarks seem to do much more than that, and if they do reveal scepticism as senseless, it's rather as a byproduct of the work, not its essential thrust. We are indeed led to see that scepticism is senseless, but this is something that the reader of the Investigations already knows, ${ }^{24}$ thanks to the criticism of the Cartesian picture of the mind.

To sum up, I have pointed out three broad and related exegetical reasons to the effect that Wittgenstein had already "dealt with" scepticism prior to writing the bulk of On Certainty. Maybe none of them is totally conclusive-I think they are, but ultimately it's for the reader to judge. However, the sheer weight of these considerations, taken together, should at least ignite a sparkle of doubt, so to speak, towards the standard interpretation. If the latter is misguided, it should provoke the possibility of an alternative reading of On Certainty, one that sees it as essentially being about something else.

\footnotetext{
${ }^{23}$ See the "Study Note on Wittgenstein" in his 2001.

${ }^{24}$ Something that even the reader of the Notebooks knows (see epigraph)!
}

\section{The Purpose of On Certainty}

If On Certainty is not a work primarily directed at providing a response to scepticism, then what is it? Considerations of space will force me to be brief here but there are some important points that can be addressed. There can be no doubt that Wittgenstein is impressed by the special status of the propositions "known" with certainty by Moore. There can also be no doubt that Wittgenstein is trying to defend the view according to which we can't be said to know these propositions, and that this defence takes up a large portion of his resources in that book. Finally, there is also no doubt that if we don't entertain such a cognitive relation to these propositions, scepticism finds itself thoroughly shaken. But the primary purpose of doing so is not to reveal scepticism as a pseudo-problem. That would be (or so it seems to me) the equivalent of smashing a mosquito with a brick — and a dead mosquito at that.

It would be more fruitful, and more plausible, to read On Certainty as being a work pertaining to the human cognitive condition. ${ }^{25}$ Cornerstone propositions play a special role in the way we deal with the world and with each other. They form the backbone of reasoning, of thought, of language, of argumentation. But what exactly is their status? Where do they belong in our conceptual scheme? Where are they situated? These are the questions - or so I contend-that had a strong hold on Wittgenstein when he worked on these remarks. He is trying to make sense of these propositions, and by doing so he is trying to make sense of our form of life, since the latter is, in good measure, determined by the cornerstone propositions that form the backbone of thought.

The recurrent themes of On Certainty fit well with the characterisation of Wittgenstein's objectives as suggested here. It is not easy to determine a definitive list of the central themes of the book, but the following three certainly play a crucial role:

- The relation we entertain with cornerstone propositions-is it epistemic or not? If not, what is that relation? Do we simply assume them? What does it mean to say that we "take them on trust”, that we don't question them but somehow accept them?

- Cornerstone propositions have the form of empirical propositions, but they differ from "regular" empirical propositions. How to account for this contrast, how should we explain it?

- There is a "feeling" of certainty attached to cornerstone propositions. What is the source of this certainty, and how is it manifested?

It seems uncontroversial that these questions are central ones in On Certainty. They were prompted upon reading Moore’s “A Defence of Common Sense”. These propositions struck Wittgenstein as peculiar. He wanted to identify their peculiarity, and by doing so he was exploring our human cognitive conditionhe was not merely, or primarily, trying to provide an answer to a sceptical threat (one that he had already dealt with anyway). His goal had a dignity (describing the human condition) that is lacking when we characterise his writing as directed towards a position (scepticism) that no one really takes seriously outside the philosophical arena (in the sense of believing it to be true, not in the sense that it's not a "serious" and "pregnant" philoso-

\footnotetext{
${ }^{25}$ See for instance Rhees when he holds that Wittgenstein thinks that cornerstone propositions "play a curious role in our speaking and thinking. An investigation of this role (and that is what the remarks from the beginning to the end of his book are) leads to a better understanding of human language, thought, and language-games” (Rhees, 2003: p. 3).
} 
phical problem). ${ }^{26}$

Wittgenstein's exploration of our form of life did not take the form of traditional philosophical theorising, but rather took, in conformity with his claims about the nature of philosophy in the Investigations and elsewhere, the descriptive form. He describes how, as a matter of fact, we use the concepts of knowledge, certainty, mistake, and the like. It is a study of the grammar of key cognitive concepts. There is nothing prescriptive ${ }^{27}-$ or normative-about his inquiry into the nature of these concepts. It is more akin to a "grammatical anthropology", a study of how human beings use certain key words. The hope is that such a study will provide an insight into our human cognitive condition —or, to put it more cautiously, will command a "clear view" of who we are qua cognitive beings. It is not a bit of philosophical theorising, but it is nevertheless difficult and deep because it is about what is somehow presupposed, unquestioned, taken for granted. To borrow Robert Brandom's expression, On Certainty is an attempt to make explicit what is implicit in our cognitive endeavours. This explicitness does not consist in constructive theoretical philosophy, but rather in a thorough description of crucial aspects of our form of life. It consists in an investigation of the nature and place of cornerstone propositions. Rush Rhees, in his rich study of On Certainty, put it well when he wrote (2003: p. 70) that cornerstones "underlie the possibility of speaking. Underlie-how? This is the main theme [of On Certainty]".

From 1915 to his death in 1951, Wittgenstein held on to two key theses in epistemology: firstly, that the problem of scepticism is a pseudo-problem, and secondly that this is because doubt does not always make sense. In his mature philosophypredominantly in the Philosophical Investigations-Wittgenstein gives grounds for both these claims. These grounds admittedly differ from those expounded in the Tractatus and in the Notebooks. However, a close study of the exposition of the nature of philosophy and the discussion of the issue of privacy in the Investigations show that these standpoints towards the traditional problem of scepticism were sufficiently established by then to invalidate a reading of On Certainty that would see it as merely another attempt to do just that. In fact, it does much more, and it would be better read as a treatise about the exploration of our human cognitive condition. That interpretation of On Certainty is consistent with the claims of the previous section, namely: it does not concern itself primarily with the problem of scepticism, it is not transcendental, and it does not con-

\footnotetext{
${ }^{26}$ It is surprising to notice that upon consulting the index of the book, one will find mention of scepticism only the once ( $\$ 37)$. This may seem to be a superficial and certainly not sufficient reason to reject the targeted reading, but nevertheless it is a surprising fact to realise that a work apparently devoted to criticise a position for which we have no other useful word than "skepticism" should barely contain it or its cognates ("skeptical", "sceptic"). While I agree that Wittgenstein often fails to mention theses that he's discussing, it seems that this case is unlike, say, "behaviourism" or "representationalism" or "psychologism". "Scepticism" is not a term of art like the aforementioned. Discussing scepticism is different from discussing an "-ism” in a typical philosophical conversation. Scepticism is not a "theory" like behaviourism. It could be argued that to discuss scepticism is in fact to engage into epistemology, into a whole field of philosophical study, one in which many of these "-isms" can figure-reliabilism, internalism, foundationalism and what not. In that sense, Wittgenstein would presumably have no difficulty in using that term and its cognates if he felt that he had to. Seen in that light, the fact that he barely used that terminology might be telling.

${ }^{27} \mathrm{I}$ mean that Wittgenstein is not putting forward a thesis that will have revisionary consequences on how we think, act, use words, etc. Not to be confused with the idea that he is studying rules and that they have a prescriptive role.
}

sist in theoretical, constructive philosophy. It is a reading of $\mathrm{On}$ Certainty that makes it continuous with Wittgenstein's mature philosophy.

\section{REFERENCES}

Cavell, S. (1979). The claim of reason. Oxford: Oxford University Press.

Coliva, A. (2010). Moore and Wittgenstein. Basingstoke: Palgrave Macmillan. doi:10.1057/9780230289697

Gascoigne, N. (2002). Scepticism. London: Acumen.

Hacker, P. M. S. (1986). Insight and illusion: Themes in the philosophy of Wittgenstein (2nd ed.). Oxford: Clarendon Press.

Kerns, A. (2004). Understanding scepticism: Wittgenstein's paradoxical reinterpretation of sceptical doubt. In D. McManus (Ed.), Wittgenstein and Scepticism (pp. 200-217). London: Routledge.

McGinn, M. (1989). Sense and certainty: A Dissolution of scepticism. Oxford: Blackwell.

McGinn, M. (2004). The everyday alternative to scepticism: Cavell and Wittgenstein on other minds. In D. McManus (Ed.), Wittgenstein and Scepticism (pp. 240-259). London: Routledge.

Moore, G. E. (1925) A defense of common sense. In T. Baldwin (Ed.), G. E. Moore: Selected writings (pp. 106-133). London: Routledge.

Moore, G. E. (1939) Proof of an external world. In T. Baldwin (Ed.), G. E. Moore: Selected writings (pp. 147-170). London: Routledge.

Moyal-Sharrock, D. (2007). Understanding Wittgenstein's On Certainty. Basingstoke: Palgrave Macmillan.

Moyal-Sharrock, D., \& Brenner, W. H. (Eds.) (2007). Readings of Wittgenstein's On Certainty. Basingstoke: Palgrave Macmillan.

Rhees, R. (2003). Wittgenstein's On Certainty: There-Like our life. Oxford: Blackwell. doi:10.1002/9780470776247

Rorty, R. (1979). Philosophy and the mirror of nature. Princeton: Princeton University Press.

Stern, R. (2000). Transcendental arguments and scepticism. Oxford: Clarendon Press.

Stroll, A. (1994). Moore and Wittgenstein On Certainty. Oxford: Oxford University Press.

Stroud, B. (1984). The Significance of philosophical scepticism. Oxford: Clarendon Press. doi:10.1093/0198247613.001.0001

Williams, M. (1991). Unnatural doubts. Oxford: Blackwell.

Wittgenstein, L. (1953). Philosophical investigations. Oxford: Blackwell.

Wittgenstein, L. (1958). The blue and brown books. Oxford: Blackwell. Wittgenstein, L. (1961). Notebooks 1914-1916. Oxford: Blackwell.

Wittgenstein, L. (1969). On Certainty. Oxford: Blackwell.

Wright, C. (1985). Facts and certainty. Proceedings of the British Academy, 71, 429-472.

Wright, C. (2001). Study note on Wittgenstein. Rails to Infinity: Essays on themes from Wittgenstein's philosophical investigations (pp. 433-443). Harvard: Harvard University Press.

Wright, C. (2002). (Anti-)sceptics simple and subtle: G. E. Moore and John McDowell. Philosophy and Phenomenological Research, 65, 330-348. doi:10.1111/j.1933-1592.2002.tb00205.x

Wright, C. (2004a). Warrant for nothing (and foundations for free?). Proceedings of theAristotelian Society Supplementary Volume, 78, 167-212.

Wright, C. (2004b). Wittgensteinian certainties. In D. McManus (Ed.), Wittgenstein and Scepticism (pp. 22-55). London: Routledge.

Wright, C. (2007). The perils of dogmatism. In S. Nuccetelli, \& G. Seay (Eds.), Themes from G. E. Moore: New Essays in Epistemology and Ethics (pp. 25-48). Oxford: Oxford University Press. 